\title{
KAJIAN KARAKTERISTIK DAS \\ (Studi Kasus DAS Tempe Sungai Bila Kota Makassar)
}

\author{
Angelica Mega Nanda ${ }^{1}$, Eko Prasetyo Nugroho ${ }^{2}$, Budi Santosa ${ }^{3}$ \\ ${ }^{1}$ Mahasiswi Program Studi Teknik Sipil, Universitas Katolik Segijapranata Semarang \\ ${ }^{2}$ Mahasiswa Program Studi Teknik Sipil, Universitas Katolik Segijapranata, Semarang \\ ${ }^{3}$ Tenaga Pengajar Program Studi Teknik Sipil, Universitas Katolik Segijapranata, \\ Semarang
}

\begin{abstract}
ABSTRAK
Kota Makassar menjadi salah satu kota dengan tingkat pembangunan infrastruktur yang tinggi dan menyebabkan perubahan lahan yang sangat signifikan. Fenomena tersebut berdampak pada pola aliran di permukaan (surface flow) dan wilayah resapan air. Tujuan penelitian tugas akhir ini adalah untuk mengetahui karakteristik hidrologi DAS Tempe Sungai Bila di Kota Makassar.

Penelitian ini menggunakan model hidrologi dengan bantuan software Hydrologic Engineering Center's Hydrologic Modeling System (HEC-HMS). Hidrograf yang dihasilkan HEC-HMS berupa outflow diolah untuk mengetahui karakteristik DAS Tempe Sungai Bila.

Hasil penelitian menunjukan bahwa parameter yang digunakan pada simulasi tersebut sesuai dengan parameter yang ada. Dari analisis outflow didapatkan karakteristik hidrologi DAS Tempe selama tahun 2003 sampai dengan tahun 2013 antara lain debit maksimum rata-rata sebesar $81,46 \mathrm{~mm}$; debit minimum rata-rata sebesar 1,05 mm; koefisien regime rata-rata sebesar 170,48 $\mathrm{mm}$ dan koefisien storage sebesar $0,06 \mathrm{~mm}$.
\end{abstract}

Kata kunci: Karakteristik hidrologi, DAS, Curah hujan rancangan, HEC-HMS

\section{PENDAHULUAN \\ 1.1 Latar Belakang}

Sebagai salah satu sumber air, sungai memegang fungsi yang sangat penting bagi kehidupan dan penghidupan masyarakat. Indonesia merupakan salah satu negara besar yang memiliki masalah banjir hingga saat ini masih terus dipelajari cara penyelesaiannya. Kota Makassar menjadi salah satu kota dengan tingkat pembangunan infrastruktur yang tinggi dan menyebabkan perubahan lahan yang sangat signifikan. Kawasan yang digunakan untuk menampung genangan air kini dialih fungsikan untuk keperluan pembangunan fisik seperti misalnya pembangunan pemukiman dan sebagainya yang berdampak pada perubahan pola aliran dipermukaan. Aliran ini selain dipengaruhi oleh karakteristik DAS dan juga sangat tergantung pada karakteristik hujan yang jatuh.

Laporan penelitian ini dibuat untuk menganalisa debit banjir pada salah satu DAS pada Sungai Bila, Makassar yaitu DAS Tempe. Data yang didapatkan kemudian akan diolah dengan mengunakan model hidrologi menggunakan software Hydrologic Engineering Center's Hydrologic Modeling System ( HEC-HMS ). Dari hasil yang didapatkan maka diharapkan debit banjir dapat mendekati kondisi 
dilapangan dan dapat digunakan untuk kepentingan penelitian selanjutnya.

\subsection{TUJUAN PENELITIAN}

Tujuan dari penelitian ini adalah :

1. Mengetahui nilai parameter model yang menggambarkan nilai karakteristik DAS Tempe di Sungai Bila dengan menggunakan software HECHMS.

2. Mengetahui karakteristik hidrologi DAS Tempe di Sungai Bila.

\section{TINJAUAN PUSTAKA}

\subsection{Hidrograf}

Menurut Hermawan (1984), hidrograf adalah suatu grafik yang menggambarkan antara tinggi muka air dengan debit. Untuk dapat merencanakan banjir rancangan, hidrograf satuan dapat diubah dari hidrograf hujan menjadi hidrograf aliran. Terdapat banyak metode yang dapat digunakan untuk mendapatkan hidrograf tergantung pada tujuan penggunaan grafik hidrograf. Untuk analisa yang lebih terperinci, hidrograf debit diplot dengan menghitung nilainilai debit langsung dari grafik catatan tinggi muka air.

Hidrograf terdiri atas tiga bagian yaitu sisi naik (rising limb), puncak (crest) dan sisi resesi (recession limb). Bentuk hidrograf dapat ditandai dengan tiga sifat pokok yaitu waktu naik (time of rise), debit puncak (peak discharge) dan waktu dasar (base time).

Bentuk hidrograf pada umumnya dipengaruhi oleh sifat hujan yang terjadi dan sifat DAS. Menurut Kennedy dan Watt (1967) dalam buku analisis hidrologi, sifat hujan yang sangat memperngaruhi hidrograf adalah intensitas hujan, lama hujan dan arah gerak hujan. Semakin tinggi intensitas hujan maka hidrograf akan naik dengan cepat, begitu pula sebaliknya.

\subsection{HEC-HMS}

Hydrologic Engineering Center's Hydrologic Modelling System (HECHMS) adalah sebuah software yang digunakan untuk mensimulasikan proses hujan-aliran pada suatu daerah aliran sungai (DAS). Model ini dirancang untuk penggunaan DAS berukuran besar.

Model ini merupakan pengembangan dari model sebelumnya yaitu HEC-1. Salah satu keunggulan dari HEC-HMS adalah telah digunakannya konsep GIS dalam penyelesaian modelnya. HEC-HMS dirancang untuk mensimulasikan proses hujan-limpasan terutama untuk DAS dengan pola dendritik. Model ini dirancang untuk penggunaan DAS berukuran besar. Data hidrograf yang dihasilkan dapat digunakan secara langsung atau dikaitkan dengan software lain untuk mengulangi berbagai masalah hidrologi seperti ketersediaan air, drainase kota dan peramalan aliran (Dasanto, 2006).

HEC-HMS dapat digunakan untuk menghitung limpasan pada permukaan penelusuran banjir pada DAS, perhitungan baseflow, presipitasi air hujan dan evaluasi bangunan pengendali air kemudian dapat digunakan untuk merepretasikan proses hidrologi. Fasilitas kompusitasi dan model dalam HEC-HMS dapat dilihat pada tabel diatas.

Input data pada HEC-HMS dapat dimasukan secara manual maupun dengan DSS (Data Storage System) karena program tersebut diintregrasi dengan sistem database. Untuk mempermudah pengoprasian sistem maka DSS dapat digunakan sebagai interface antara berbagai model yang sudah terintergasi dan komponen yang ada dalam HEC-HMS. 
Tabel 2.1 Fasilitas komputasi dan model pada HEC-HMS

\begin{tabular}{|c|c|c|}
\hline Komputasi & \multicolumn{2}{|c|}{ Model } \\
\hline Precipitation & $\begin{array}{l}\text { User hytograph } \\
\text { User gage } \\
\text { weighting } \\
\text { Inverse } \\
\text { distance gage } \\
\text { weights }\end{array}$ & $\begin{array}{l}\text { Gridded } \\
\text { precipitation } \\
\text { Frequency } \\
\text { storm } \\
\text { Standard } \\
\text { project storm }\end{array}$ \\
\hline Volume runoff & $\begin{array}{l}\text { Initial and } \\
\text { constant rate } \\
\text { SCS curve } \\
\text { number }(C N) \\
\text { Gridded SCS } \\
\text { CN }\end{array}$ & $\begin{array}{l}\text { Green and } \\
\text { ampt } \\
\text { Deficit and } \\
\text { constant rate } \\
\text { Soil moisture } \\
\text { accounting } \\
\text { (SMA) } \\
\text { Grindded SMA }\end{array}$ \\
\hline $\begin{array}{l}\text { Direct runoff } \\
\text { (overland flow and } \\
\text { interflow) }\end{array}$ & $\begin{array}{l}\text { Constant } \\
\text { monthly } \\
\text { Exponential } \\
\text { recession } \\
\text { Linier reservoir }\end{array}$ & $\begin{array}{l}\text { SCS UH } \\
\text { Modclark } \\
\text { Kinematic } \\
\text { wave }\end{array}$ \\
\hline Baseflow & $\begin{array}{l}\text { Kinematic wave } \\
\text { Lag } \\
\text { Modified puls } \\
\text { Muskingum }\end{array}$ & \\
\hline Channel flow & $\begin{array}{l}\text { Muskingum- } \\
\text { cunge standart } \\
\text { section } \\
\text { Muskingium- } \\
\text { cunge 8-point } \\
\text { section }\end{array}$ & \\
\hline
\end{tabular}

Sumber : Techical Reence Manual HEC-HMS

(2000)

\subsection{Kalibrasi dan Parameter Model pada HEC-HMS}

untuk menentukan parameterparameter dari karakteristik DAS seperti CN Number), luasan daerah kedap air (imperviousness), resapan awal (initial abstraction) atau nilai baseflow untuk mendapatkan hasil yang paling mendekati kondisi di lapangan.

Debit banjir hidrograf yang dihasilkan oleh HEC-HMS dalam proses kalibrasi digunakan sebagai parameter. Berikut ini adalah nilai parameter yang diijinkan dalam permodelan HEC-HMS (tabel 2.2).
Tabel 2.2 Nilai parameter kalibrasi model HEC-HMS

\begin{tabular}{|c|c|c|c|}
\hline Model & Parameter & Min & Max \\
\hline SCS Loss & $\begin{array}{l}\text { Initial } \\
\text { Abstraction } \\
\text { Curve } \\
\text { number }\end{array}$ & $\begin{array}{l}0 \mathrm{~mm} \\
1\end{array}$ & $\begin{array}{l}500 \\
\mathrm{~mm} \\
100\end{array}$ \\
\hline$S C S U H$ & Lag & $0,1 \mathrm{~min}$ & $\begin{array}{l}30000 \\
\min \end{array}$ \\
\hline Baseflow & $\begin{array}{l}\text { Initial } \\
\text { baseflow } \\
\text { Recession } \\
\text { factor } \\
\text { Flow-to- } \\
\text { peak ratio } \\
\end{array}$ & $\begin{array}{l}0 \mathrm{~m}^{3} / \mathrm{s} \\
0,000011 \\
0\end{array}$ & $\begin{array}{l}100000 \\
\mathrm{~m}^{3} / \mathrm{s} \\
- \\
1\end{array}$ \\
\hline $\begin{array}{c}\text { Muskingum } \\
\text { Routing }\end{array}$ & $\begin{array}{l}\text { K } \\
x \\
\text { Number of } \\
\text { steps }\end{array}$ & $\begin{array}{l}0,1 \mathrm{hr} \\
0 \\
1\end{array}$ & $\begin{array}{l}150 \mathrm{hr} \\
0,5 \\
100\end{array}$ \\
\hline
\end{tabular}

Sumber: Panduan HEC-HMS (Suhartanto, 2008)

\subsection{Parameter Dalam HEC-HMS}

Dalam HEC-HMS diperlukan beberapa parameter sebagai pengontrol hubungan dari sistem Input ke sistem output. Tabel 2.3 merupakan parameter-parameter yang digunakan dalam HEC-HMS. 
Tabel 2.3 Parameter HEC-HMS

Sumber :USACE-HEC (2000)

\section{METODE PENELITIAN}

\subsection{Lokasi Studi}

Lokasi yang diambil menjadi studi kasus pada penelitian ini adalah salah satu DAS yang berada di Kota Makassar, yaitu DAS Tempe, Sungai Bila. DAS Tempe dalam penelitian ini memiliki titik kontrol pada Tanru Tedong.

\subsection{Diagram Alir Umum}

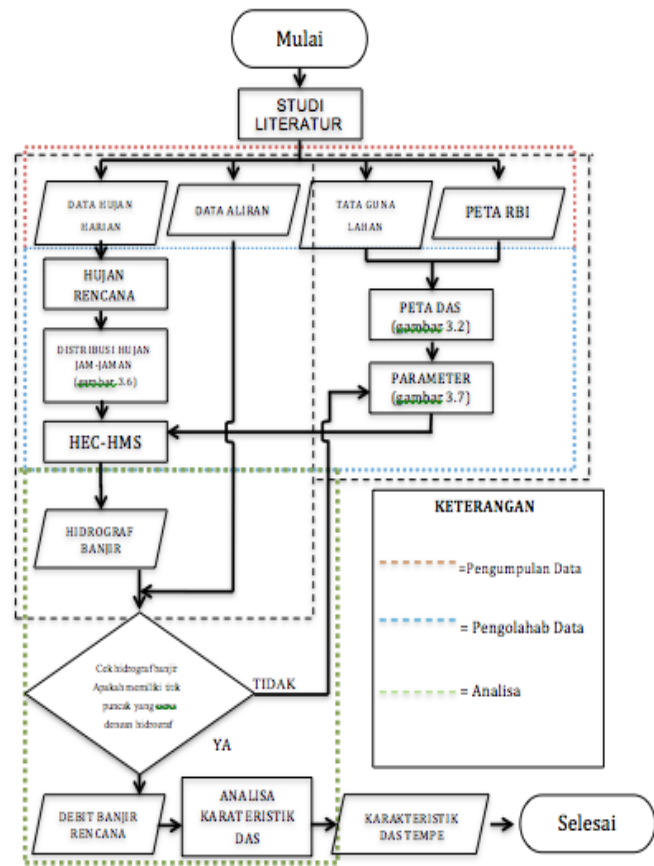

Gambar 3.1 Bagan Alir Umum

\subsubsection{Bagan Alir Penentuan Batas Das Tempe}

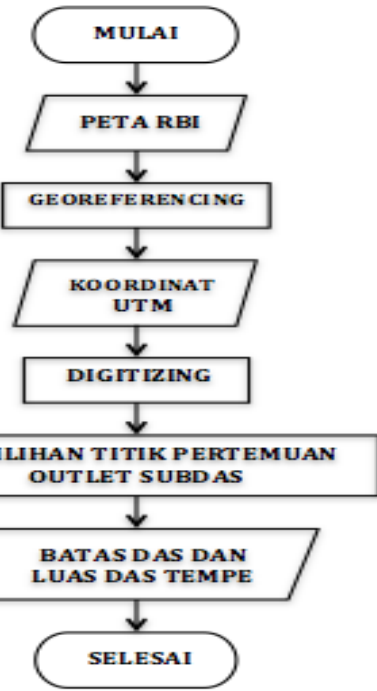

G-SMART Volume 1 | Nomor 1 | 2017

\begin{tabular}{|c|c|}
\hline Metode & Parameter \\
\hline \multirow{2}{*}{ Initial and Constant Rate Loss } & Initial loss \\
\hline & Constant Rate \\
\hline \multirow[t]{2}{*}{ SCS Loss } & iInitial Abstraction \\
\hline & Curve Number \\
\hline \multirow[t]{3}{*}{ Green and Ampt Loss } & Moisture deficit \\
\hline & Hydraulic conductivity \\
\hline & Wetting front suction \\
\hline \multirow[t]{3}{*}{ Deficit and Constant Rate Loss } & Initial deficit \\
\hline & Maximumj deficit \\
\hline & Deficit recovery factor \\
\hline \multirow[t]{2}{*}{ Clark's UH } & Time of concemtration \\
\hline & Strorage coefficient \\
\hline \multirow[t]{2}{*}{ Snyder's UH } & Lag \\
\hline & $C p$ \\
\hline$S C S$ UH & Lag \\
\hline Kinematic Wave & Manning's $n$ \\
\hline \multirow[t]{3}{*}{ Baseflow } & Initial Baseflow \\
\hline & Recession factor \\
\hline & Flow-to-peak Ratio \\
\hline \multirow[t]{3}{*}{ Muskingum Routing } & $K$ \\
\hline & $X$ \\
\hline & Number of Steps \\
\hline Kinematic Wave Routing & $N$-Value Factor \\
\hline Lag Routing & Lag \\
\hline
\end{tabular}

Gambar 3.2 Bagan Alir Penentuan Batas Das

3.2.2 Bagan Alir Poligon Thiessen

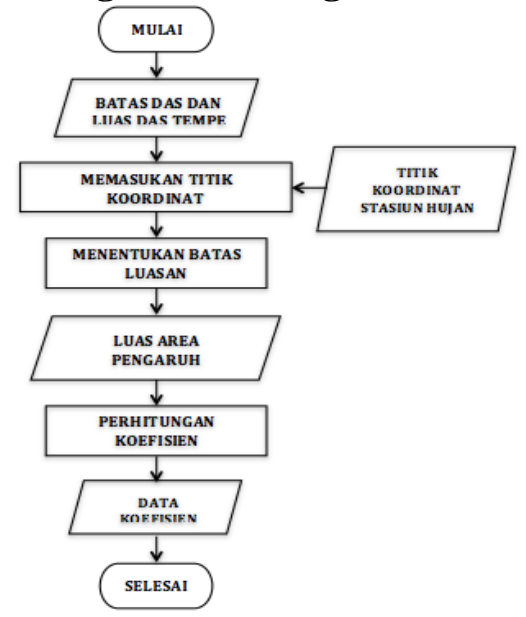

Gambar 3.3 Bagan Alir Poligon Thiessen

3.2.3 Bagan Alir Perkiraan Curah Hujan Rancangan 


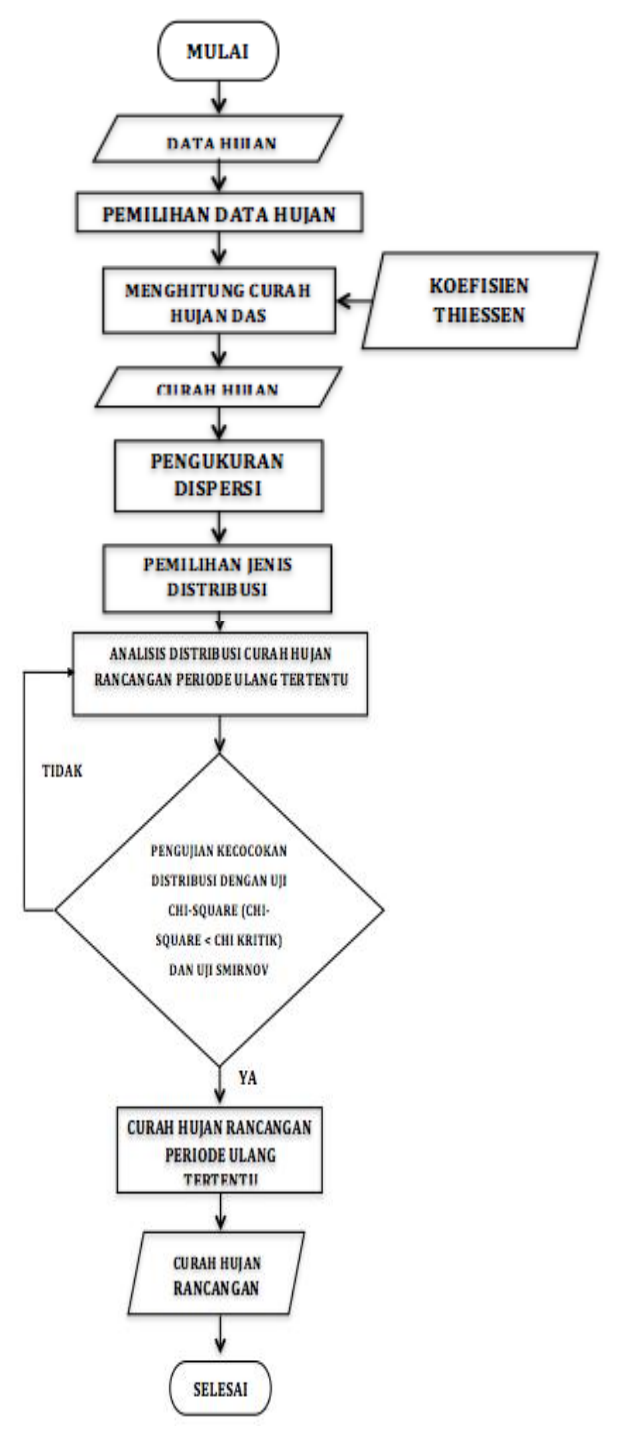

Gambar 3.4 Bagan Alir Penentuan Curah Hujan Rancangan

\subsubsection{Bagan Alir Distribusi Hujan Jam-jaman}

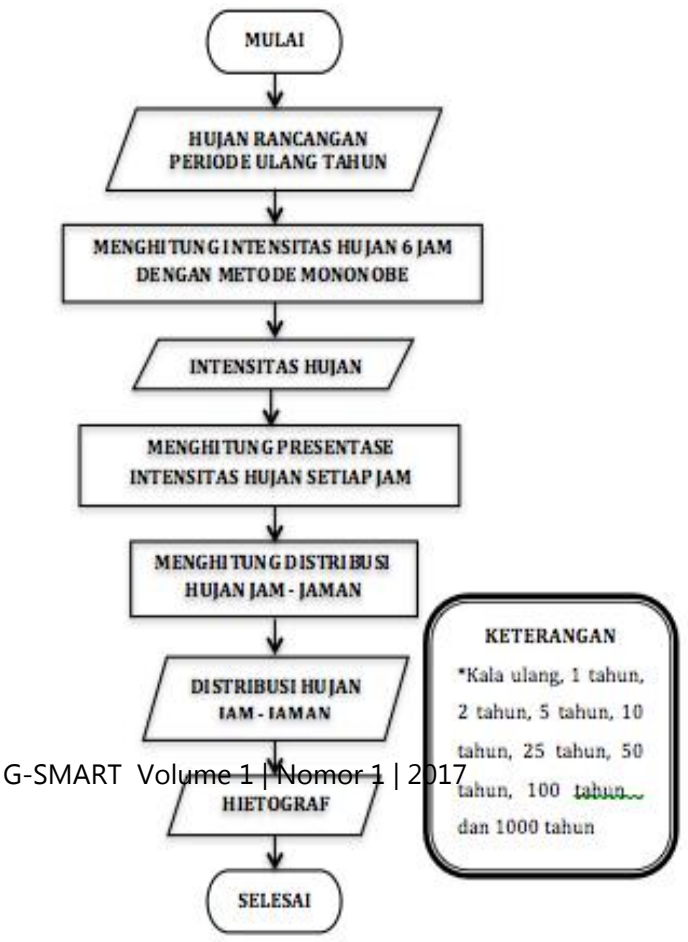

Gambar 3.5 Bagan Alir Distribusi Hujan Jam-Jaman

\subsubsection{Bagan Alir Kalibrasi}

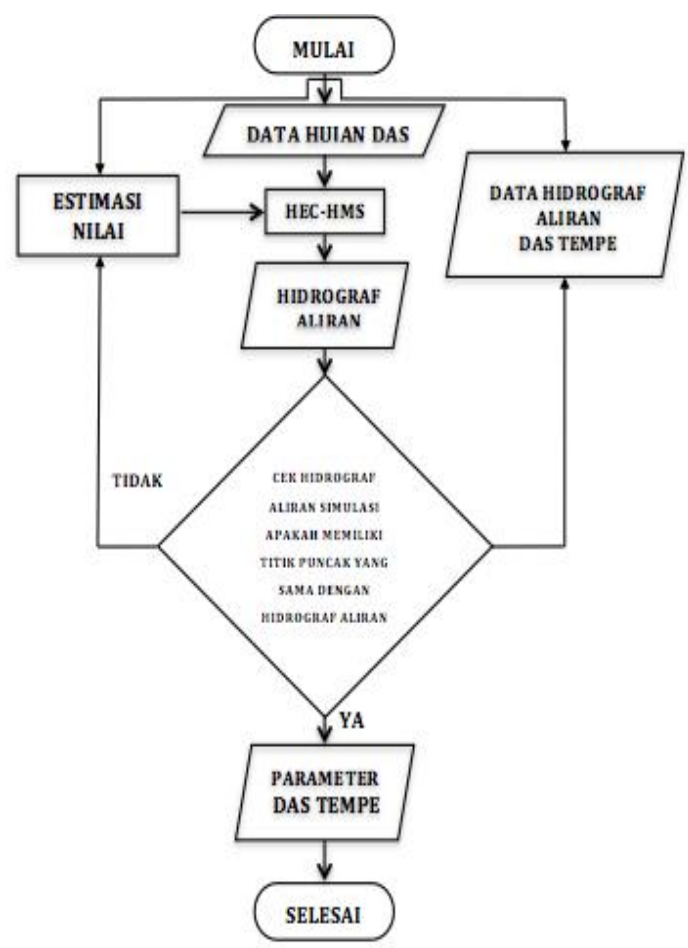

Gambar 3.6 Bagan Alir Kalibrasi

\section{ANALISIS DAN PEMBAHASAN 4.1 Parameter Model DAS Tempe \\ Pada proses menentukan} parameter model, perlu dilakukan proses kalibrasi. Langkah awal yang dilakukan adalah dengan mengatur nilai estimasi pada parameter setiap metode sehingga data yang akan dihasilkan berupa outflow simulasi menjadi hampir sama dengan data yang ada dilapangan.

Data curah hujan yang telah diolah kemudian di input kedalam gage untuk mendapatkan hidrograf simulasi yang akan dibandingkan dengan hidrograf yang ada dilapangan. Data yang digunakan adalah data curah hujan bulan 1 April 2013 sampai dengan 
tanggal 31 Juli 2013 dengan interval waktu 1 hari. Berdasarkan uji parameter model yang telah dilakukan, didapatkan hasil outflow yang hampir sesuai dengan parameter yang ada di lapangan. Hasil nilai parameter model yang digunakan dalam model simulasi penelitian ini adalah sebagai berikut.

Tabel 4.1 Nilai Parameter Baseflow

\begin{tabular}{|l|c|c|}
\hline \multirow{2}{*}{ SubDAS } & \multicolumn{2}{|c|}{ Base flow } \\
\cline { 2 - 3 } & $\begin{array}{c}\text { Initial Discharge } \\
\left(\mathbf{m}^{\mathbf{3}} / \mathbf{s}^{\mathbf{2}}\right)\end{array}$ & $\begin{array}{c}\text { Recession } \\
\text { Constant }\end{array}$ \\
\hline SubDAS 1 & 0 & 0.14 \\
\hline SubDAS 2 & 0 & 0.13 \\
\hline SubDAS 3 & 0 & 0.12 \\
\hline SubDAS 4 & 0 & 0.11 \\
\hline SubDAS 5 & 0 & 0.15 \\
\hline SubDAS 6 & 0 & 0.14 \\
\hline SubDAS 7 & 0 & 0.13 \\
\hline SubDAS 8 & 0 & 0.12 \\
\hline SubDAS 9 & 0 & 0.11 \\
\hline SubDAS 10 & 0 & 0.15 \\
\hline SubDAS 11 & 0 & 0.14 \\
\hline SubDAS 12 & 0 & 0.13 \\
\hline SubDAS 13 & 0 & 0.12 \\
\hline SubDAS 14 & 0 & 0.11 \\
\hline SubDAS 15 & 0 & 0.15 \\
\hline SubDAS 16 & 0 & 0.14 \\
\hline SubDAS 17 & 0.1 & 0.13 \\
\hline SubDAS 18 & 0.1 & 0.12 \\
\hline SubDAS 19 & 0.1 & 0.12 \\
\hline
\end{tabular}

Tabel 4.2 Nilai Parameter Snyder's UH

\begin{tabular}{|l|c|c|}
\hline \multirow{2}{*}{ SubDAS } & \multicolumn{2}{|c|}{ Tansform } \\
\cline { 2 - 3 } & $\begin{array}{c}\text { Lag Time } \\
(\boldsymbol{H r})\end{array}$ & Peaking Coef. \\
\hline SubDAS 1 & 0.1 & 1 \\
\hline SubDAS 2 & 0.1 & 1 \\
\hline SubDAS 3 & 0.1 & 1 \\
\hline SubDAS 4 & 0.1 & 1 \\
\hline SubDAS 5 & 0.1 & 1 \\
\hline SubDAS 6 & 0.1 & 1 \\
\hline SubDAS 7 & 0.1 & 1 \\
\hline SubDAS 8 & 0.1 & 1 \\
\hline SubDAS 9 & 0.1 & 1 \\
\hline SubDAS 10 & 0.1 & 1 \\
\hline SubDAS 11 & 0.1 & 1 \\
\hline
\end{tabular}

\begin{tabular}{|l|c|l|}
\hline SubDAS 12 & 0.1 & 1 \\
\hline SubDAS 13 & 1 & 1 \\
\hline SubDAS 14 & 0.1 & 1 \\
\hline SubDAS 15 & 0.1 & 1 \\
\hline SubDAS 16 & 0.1 & 1 \\
\hline SubDAS 17 & 0.1 & 1 \\
\hline SubDAS 18 & 0.1 & 1 \\
\hline SubDAS 19 & 0.1 & 1 \\
\hline
\end{tabular}

Tabel 4.3 Nilai Parameter Initial Loss and Constnt Rate

\begin{tabular}{|c|c|c|c|}
\hline \multirow[b]{2}{*}{ SubDAS } & \multicolumn{3}{|c|}{ Loss } \\
\hline & $\begin{array}{l}\text { Initial } \\
\text { Loss } \\
(\mathrm{mm})\end{array}$ & $\begin{array}{l}\text { Constan } \\
\text { Rate } \\
(\mathrm{mm} / \mathrm{hr})\end{array}$ & Impervious (\%) \\
\hline SubDAS 1 & 16 & 1 & 3 \\
\hline SubDAS 2 & 16 & 5 & 3 \\
\hline SubDAS 3 & 16 & 5 & 3 \\
\hline SubDAS 4 & 16 & 5 & 3 \\
\hline SubDAS 5 & 16 & 5 & 3 \\
\hline SubDAS 6 & 16 & 5 & 3 \\
\hline SubDAS 7 & 16 & 5 & 3 \\
\hline SubDAS 8 & 16 & 5 & 3 \\
\hline SubDAS 9 & 16 & 5 & 3 \\
\hline SubDAS 10 & 16 & 5 & 3 \\
\hline SubDAS 11 & 16 & 5 & 3 \\
\hline SubDAS 12 & 16 & 5 & 3 \\
\hline SubDAS 13 & 16 & $\overline{1}$ & 3 \\
\hline SubDAS 14 & 16 & $\overline{1}$ & 3 \\
\hline SubDAS 15 & 16 & 1 & 3 \\
\hline SubDAS 16 & 16 & 1 & 3 \\
\hline SubDAS 17 & 16 & 1 & 3 \\
\hline SubDAS 18 & 16 & 1 & 3 \\
\hline SubDAS 19 & 16 & 1 & 3 \\
\hline
\end{tabular}

Tabel 4.4 Nilai Parameter Recession

Dari nilai parameter yang digunakan didapatkan hasil outflow berupa grafik hidrograf yang dibandingkan dengan data aliran selama 4 bulan bulan 1 April 2013 sampai dengan tanggal 31 Juli 2013 (Gambar 4.1) dan grafik hidrograf selama 10 tahun dari 1 januari 2003 sampai dengan 31 desember 2013 (gambar 4.2). 
Gambar 4.1 Grafik Curah Hujan dan Outflow Simulasi HEC-HMS 4 Bulan

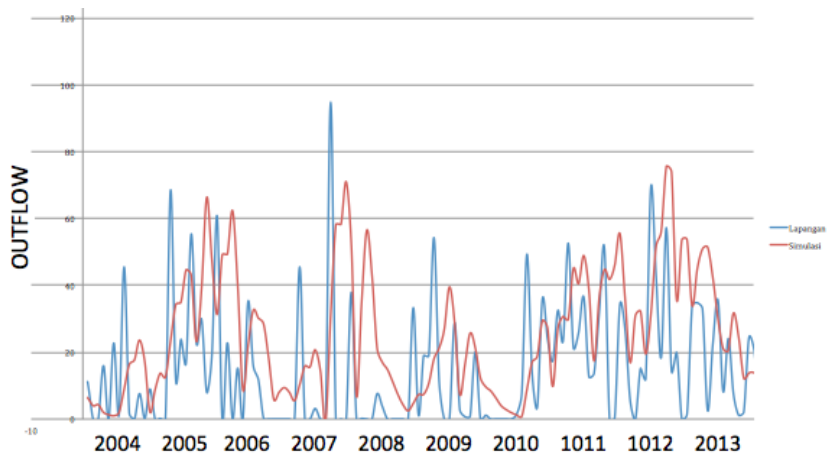

Gambar 4.2 Grafik Curah Hujan dan Outflow Simulasi HEC-HMS 10 Tahun

\subsection{Karakteristi Hidrologi DAS Tempe}

Setelah outflow dari simulasi HEC-HMS diketahui maka langkah selanjutnya adalah menghitung nilainilai karakteristik dari DAS Tempe berupa debit maksimum, debit minimum, debit rerata, koefisien regime dan koefisien storage. Berikut ini adalah tabel perhitungan Karakteristik DAS Tempe dengan menggunakan outflow dari simulasi HEC-HMS.

Tabel 4.36 Tabel Karakteristik DAS Tempe

\begin{tabular}{|c|c|c|c|c|c|}
\hline Tahun & $\begin{array}{l}\text { Debit } \\
\text { Maksimum }\end{array}$ & $\begin{array}{l}\text { Debit } \\
\text { Minimum }\end{array}$ & $\begin{array}{l}\text { Debit } \\
\text { Rerata }\end{array}$ & $\begin{array}{l}\text { Koef. } \\
\text { Regime }\end{array}$ & $\begin{array}{l}\text { Koef. } \\
\text { Storage }\end{array}$ \\
\hline & Qmax & Qmin & Qav & Qmax/Qmin & Qmin/Qav \\
\hline 2003 & 122.9 & 10.7 & 22.25 & 11.48 & 0.48 \\
\hline 2004 & 122.9 & 0 & 22.24 & - & 0 \\
\hline 2005 & 238.6 & 0 & 11.12 & - & 0 \\
\hline 2006 & 34.6 & 0 & 1.69 & - & 0 \\
\hline 2007 & 23.9 & 0.3 & 3.08 & 79.7 & 0.09 \\
\hline 2008 & 81.1 & 0.4 & 5.56 & 202.75 & 0.07 \\
\hline 2009 & 24 & 0 & 2.63 & - & 0 \\
\hline 2010 & 38.2 & 0 & 5.77 & - & 0 \\
\hline 2011 & 37.2 & 0 & 3.07 & - & 0 \\
\hline 2012 & 77.6 & 0.2 & 6.91 & 388 & 0.02 \\
\hline${ }^{2013}-3 M$ & V5.1 & Nomor 1 & 2017 & - & 0 \\
\hline Rata-rat: & 81.46 & 1.05 & 8.82 & 170.48 & 0.06 \\
\hline
\end{tabular}

\begin{tabular}{|c|c|c|}
\hline \multirow{2}{*}{ SubDAS } & \multicolumn{2}{|c|}{ Maskingum } \\
\hline & $\mathbf{K}$ & $\mathbf{X}$ \\
\hline SubDAS 1 & 50 & 0.5 \\
\hline SubDAS 2 & 50 & 0.5 \\
\hline SubDAS 3 & 30 & 0.5 \\
\hline SubDAS 4 & 30 & 0.5 \\
\hline SubDAS 5 & 30 & 0.5 \\
\hline SubDAS 6 & 50 & 0.5 \\
\hline SubDAS 7 & 30 & 0.5 \\
\hline SubDAS 8 & 35 & 0.5 \\
\hline SubDAS 9 & 60 & 0.5 \\
\hline SubDAS 10 & 30 & 0.5 \\
\hline SubDAS 11 & 35 & 0.5 \\
\hline SubDAS 12 & 40 & 0.5 \\
\hline SubDAS 13 & 34 & 0.5 \\
\hline SubDAS 14 & 38 & 0.5 \\
\hline SubDAS 15 & 23 & 0.5 \\
\hline SubDAS 16 & 25 & 0.5 \\
\hline SubDAS 17 & 25 & 0.5 \\
\hline SubDAS 18 & 25 & 0.5 \\
\hline SubDAS 19 & 25 & 0.5 \\
\hline
\end{tabular}

Dari tabel diatas diketahui bahwa karakteristik DAS Tempe selama tahun 2003 sampai dengan tahun 2013 antara lain debit maksimum rata-rata sebesar $81,46 \mathrm{~mm}$ dan debit minimum rata-rata sebesar $1,05 \mathrm{~mm}$; koefisien regime rata-rata sebesar $170,48 \mathrm{~mm}$ dan koefisien storage sebesar 0,06 mm.

\section{PENUTUP}

\subsection{Kesimpulan}

Dari analisis yang telah dilakukan, kesimpulan yang dapat diambil adalah sebagai berikut:

1. Nilai parameter yang sesuai dengan kondisi DAS Tempe yaitu adalah sebagai berikut:
a. Initial Loss : $1 \mathrm{~mm}$
b. Constant Rate: $1-5 \mathrm{~mm} / \mathrm{hr}$
c. Impervious : $3 \%$
d. Lag Time : 0,1-1 hr 
e. Peaking Coeffisient: 1

f. Initial Discharge : $0-0,1$ $\mathrm{m}^{3} / \mathrm{s} / \mathrm{km}^{2}$

g. Recession Constant: $0,1 \quad-$ 0,15

h. Maskingum K: $25-60 \mathrm{hr}$

i. Maskingum X: 0,5

2. Karakteristik hidrologi DAS Tempe selama tahun 2003 sampai dengan tahun 2013 adalah sebagai berikut:
a. Debit maksimum rata-rata adalah sebesar $81,46 \mathrm{~mm}$.
b. Debit minimum rata-rata adalah sebesar 1,05 $\mathrm{mm}$.
c. Koefisien regime rata-rata adalah sebesar 170,48 mm.
d. Koefisien storage adalah sebesar 0,06 $\mathrm{mm}$.

\subsection{Saran}

Sesuai dengan hasil akhir analisis karakteristik debit banjir DAS Tempe, maka saran yang dapat penulis berikan adalah sebagai berikut:

1. Pada setiap model hidrologi yang akan diaplikasikan perlu untuk dilakukan kalibrasi agar hasil simulasi model dapat sesuai dengan parameter yang ada dilapangan.

2. Untuk pengujian DAS lain yang ada di Makassar dapat menggunakan permodelan hidrologi dengan HEC-HMS.

3. Pemerintah Kota Makassar diharapkan untuk lebih memperhatikan kelengkapan data yang ada, sehingga dalam penelitian selanjutnya dalam proses pengolahan data dan analisa dapat lebih mudah untuk dikaji khususnya untuk DAS yang berpengaruh pada Kota Makassar. 